\title{
Primitive portal vein thrombosis
}

INSERM

\section{Source}

INSERM. (1999). Orphanet: an online rare disease and orphan drug data base. Primitive portal vein thrombosis. ORPHA:854

Portal vein thrombosis (PVT) is associated with acute (recent) or chronic (long-standing) thrombosis of the portal system. 